\title{
Pamidronate Disodium
}

National Cancer Institute

\section{Source}

National Cancer Institute. Pamidronate Disodium. NCI Thesaurus. Code C1345.

The disodium salt of the synthetic bisphosphonate pamidronate. Although its mechanism of action is not completely understood, pamidronate appears to adsorb to calcium phosphate crystals in bone, blocking their dissolution by inhibiting osteoclast-mediated bone resorption. This ag ent does not inhibit bone mineralization and formation. 